\title{
Influence of Temperature and Time of Year on Colonization of Bermudagrass Roots by Ophiosphaerella herpotricha
}

\author{
N. R. Walker, Department of Entomology and Plant Pathology, Oklahoma State University, Stillwater 74078; \\ T. K. Mitchell, Department of Plant Pathology, North Carolina State University, Raleigh 27695; and A. N. Morton \\ and S. M. Marek, Department of Entomology and Plant Pathology, Oklahoma State University, Stillwater 74078
}

\begin{abstract}
Walker, N. R., Mitchell, T. K., Morton, A. N., and Marek, S. M. 2006. Influence of temperature and time of year on colonization of bermudagrass roots by Ophiosphaerella herpotricha. Plant Dis. 90:1326-1330

The influence of temperature on the infection of bermudagrass seedlings by Ophiosphaerella herpotricha and colonization of plants in the field was investigated. Bermudagrass seedlings (cv. Jackpot) inoculated with $O$. herpotricha exhibited dark lesions after 8 days. Root lesion length was greatest at $17^{\circ} \mathrm{C}$ and was similar for all temperatures examined below $21^{\circ} \mathrm{C}$. Seedlings grown at 25 or $30^{\circ} \mathrm{C}$ had small lesions that remained similar in size when evaluated at 8 and 10 days post inoculation. Colonization of bermudagrass roots from field plots were examined in July, October, and November of 2003 and 2004. In 2003, no differences between sampling dates were observed for plants sampled from the edge of the spring patch in 5.4-cm increments to a total distance of $21.6 \mathrm{~cm}$. In 2004, July and October samples were similar; however, an increase in root colonization was found between the October and November samplings. These studies suggest that infection and colonization of bermudagrass roots by $O$. herpotricha occurs over a wide range of cool soil temperatures, occurs in the spring, and can be variable in the autumn.
\end{abstract}

Additional keywords: Cynodon dactylon, Ophiosphaerella korrae, O. narmari, spring dead spot

Bermudagrass (Cynodon dactylon (L.) Pers. and C. dactylon $\times$ C. transvaalensis Burtt-Davy) is the predominant turfgrass used for residential lawns, commercial landscapes, athletic fields, and golf course fairways and roughs in the southern United States. Multiple traits of bermudagrass, including heat tolerance, fine texture, deep green color, and desirable pest resistance profile, have led to its widespread use in this region. Bermudagrass has a stoloniferous growth habit that permits rapid spreading growth and recovery from injury or wear. In addition, the stolons and rhizomes provide a mechanism for regrowth of the grass following periods of adverse environmental conditions such as drought or cool temperatures. This trait is important for survival in the "transition zone" of the United States, where the plants enter cool temperature-induced dormancy in late autumn and remain dormant until soil temperatures are sufficiently warm for regrowth in the spring.

In this transition zone, the most devastating and important disease of bermudagrass is spring dead spot $(6,9)$. The disease

Corresponding author: N. R. Walker

E-mail: nathan.walker@okstate.edu

Accepted for publication 1 June 2006.

DOI: 10.1094/PD-90-1326

(C) 2006 The American Phytopathological Society is caused by three species of fungi: Ophiosphaerella herpotricha (Fr.:Fr.) J. C. Walker, O. korrae (J. C. Walker \& A. M. Smith) Shoemaker \& C. E. Babcock, or $O$. narmari (J. C. Walker \& A. M. Smith) Wetzel, Hubert \& Tisserat. In the south-central plains states of the United States (i.e., Oklahoma and Kansas), the disease is caused primarily by $O$. herpotricha $(15,18,21)$. In other regions of the United States, the disease is caused primarily by $O$. korrae $(2,4)$, and, in Australia and New Zealand, the causal agent is $O$. narmari $(10,12,19)$.

Symptoms of the disease typically begin to appear in the United States in early spring as nonaffected plants become active and begin to produce new, green leaves. The majority of affected plants do not survive, resulting in noticeable patches that typically appear as sunken, circular dead areas of various sizes $(<1 \mathrm{~m}$ in diameter) in healthy swards of bermudagrass. Dead patches generally increase in size each succeeding year $(6,9)$. Larger patches of disease reappear in the same location annually and reestablishment of turfgrass in the dead area is initiated from surviving plants in the patch or from the edge. Regrowth of bermudagrass into the affected areas can be slow, and it has been suggested that a toxin in the soil is responsible $(5,17)$. Over time, the discreet circular patches become irregular, possibly becoming ring- or arc-like in shape, and, eventually, may disappear. Individually, dead plants in the spring usually exhibit a char- acteristic dark brown or black discoloration of the stolons, rhizomes, and crowns.

Numerous environmental and host factors are known to influence the appearance and severity of spring dead spot, including temperature, soil type, soil compaction, soil disturbance, bermudagrass cultivar, nitrogen fertility, mowing height, and nitrogen source $(1,3,7,8,13,22)$. The influence of temperature on the disease has been studied extensively because cold temperature-induced plant dormancy and cool soil temperatures are required for the disease development. On the other hand, bermudagrass growth is favored by warm temperatures $\left(>25^{\circ} \mathrm{C}\right)$ and restricted during periods of cooler temperatures $(9,16)$.

The influence of temperature on the ability of the causal fungus to infect, colonize, and grow in planta are not well understood. Temperature studies conducted with $O$. korrae revealed that ectotrophic hyphae were present on bermudagrass roots when plants were grown at 25 and $30^{\circ} \mathrm{C}$ (4). However, plant mortality was only observed at 15 and $20^{\circ} \mathrm{C}$. For studies conducted with $O$. herpotricha, a reduced root weight was observed for plants grown at 15 and $25^{\circ} \mathrm{C}$, with no plant mortality observed (15). It was first suggested by Smith that temperatures from 10 to $20^{\circ} \mathrm{C}$ were most conducive for disease caused by O. narmari in Australia (11). Tisserat et al. suggested that infection and colonization of bermudagrass roots by $O$. herpotricha could occur for temperatures from 10 to $25^{\circ} \mathrm{C}$ (15). Crahay et al. (2) hypothesized that the pathogen probably was infecting plant roots in both the spring and fall when soil temperatures were above $10^{\circ} \mathrm{C}$. However, cool autumn soil temperatures, the appearance of symptoms in the spring, reports of effective autumn fungicide applications, and indications that factors that delay dormancy increase disease severity have placed emphasis on the autumn as the period of greatest disease activity. Thus, the objectives of the present study were to (i) evaluate the influence of temperature on the in vitro colonization of bermudagrass seedling roots by $O$. herpotricha and (ii) evaluate the colonization of established bermudagrass plants in vivo from summer through autumn.

\section{MATERIALS AND METHODS}

Growth chamber temperature studies. Bermudagrass seed (cv. Jackpot) were 
surface sterilized in $1 \% \mathrm{AgNO}_{3}$ (SigmaAldrich, St. Louis) for $1 \mathrm{~min}$. Seed were washed in sterile, deionized water, transferred to petri dishes containing potato dextrose agar (PDA) (Sigma Chemical), and stored in the dark. After 4 to 5 days, five seedlings, free of fungal contamination, were selected and transferred to sterile paper towels with leaves protruding beyond the towel. Paper towels were saturated with sterile water, placed in a 100-ml beaker with sterile water, and sealed in a plastic bag (Ziploc storage bag; S.C Johnson, Inc., Racine, WI) to retain moisture. The bags were placed inside transparent, sterile plastic boxes and placed in a growth chamber at $16^{\circ} \mathrm{C}$ with a 12 -h photoperiod for 10 days prior to inoculation. After 10 days, a single root of each of four plants was inoculated once with a $1-\mathrm{mm}^{2}$ agar plug obtained from the edge of a 2-weekold culture of $O$. herpotricha. A fifth plant served as a control.

Boxes were maintained in a growth chamber at $12,16,17,19,21,25$, or $30^{\circ} \mathrm{C}$ with a 12-h photoperiod. Root colonization was based on the length of root discoloration. Internal colonization of root tissue was confirmed in preliminary studies by surface sterilizing roots as described previously and comparing root discoloration with fungal growth from roots. Fungal growth from the root was present at the leading edges of the lesion and from within the lesion. Discoloration was measured twice using a stereomicroscope at 8 and 10 days after inoculation. Each study was replicated three times for all temperatures. Orthogonal contrasts were conducted using SAS (version 9.1; SAS Institute, Cary, NC).

Seasonal field studies. Field studies were conducted at the Oklahoma State University Plant Pathology Research Farm in Stillwater, OK in a Norge clay loam soil, pH 6.9. Bermudagrass (cv. Jackpot) was established in early summer 2000 using sprigs produced from a greenhousegrown plant. The turf was mowed to a height of $5 \mathrm{~cm}$ weekly, irrigated two to three times weekly, and fertilized every 2 weeks from late April through August with $\mathrm{N}$ at $48.9 \mathrm{~kg} / \mathrm{ha}$. The stand was inoculated in 88 locations in the fall of 2001 with $10 \mathrm{~g}$ of wheat seed colonized by $O$. herpotricha on a $1.52-\mathrm{m}$ spacing. A putting green cupcutter $(10.8 \mathrm{~cm}$ in diameter by 4 to $6 \mathrm{~cm}$ deep) was used to remove a soil core prior to placement of the inoculum, and a steel bolt was placed in the center of the inoculation point. Following two springs, welldefined spring dead spot patches were present where the inoculum was placed. In spring 2003, all patches were traced using a clear plastic tarp and permanent steel plates were positioned outside the stand to facilitate the locating of each patch using the tarp and recording future patch size. Starting on 23 July 2003, a soil profile sampling probe (rectangular; 10.8 by 2.5 by 6 to $8 \mathrm{~cm}$, length by width by depth) was used to collect four pairs of samples at right angles to one another and radiating $21.6 \mathrm{~cm}$ from the edge of a previous year's well-defined, nearly circular, arbitrarily selected spring dead spot patch (Fig. 1; 30 to $40 \mathrm{~cm}$ in diameter). On this date, the patches were covered completely by apparently healthy grass; no symptoms of disease or past disease injury were present. Samples included plants and soil and each sample was divided in half to yield a total of 16 5.4-by-2.5-cm samples per patch. This process was repeated for two more patches, except for one patch that could only be sampled in three directions due to herbicide injury. The three patches were sampled two more times, on 6 October and 3 November. These successive samples were taken from locations 2 to $3 \mathrm{~cm}$ counterclockwise around the circumference of the patch from the previous sampling locations, respectively (Fig. 1). No active symptoms or previous disease injury were apparent in the patch or areas where the samples were collected in the autumn. Soil temperatures at 5 and $10 \mathrm{~cm}$ under sod were determined using an Oklahoma Mesonet weather station located $190 \mathrm{~m}$ from the study site.

To determine the percentage of roots colonized by $O$. herpotricha, a method modified after Smith (10) was utilized. Roots (1 to $8 \mathrm{~cm}$ ) were separated from soil and washed in water for 3 to $4 \mathrm{~min}$, then surface sterilized in a solution of $0.525 \%$ $\mathrm{NaOCl}$ for 4 min, washed in sterile, deionized water, and transferred to PDA-RAD selective medium containing full-strength PDA (potato dextrose broth at $24 \mathrm{~g} / \mathrm{liter}$ [Sigma-Aldrich] and agar at $15 \mathrm{~g} / \mathrm{liter}$

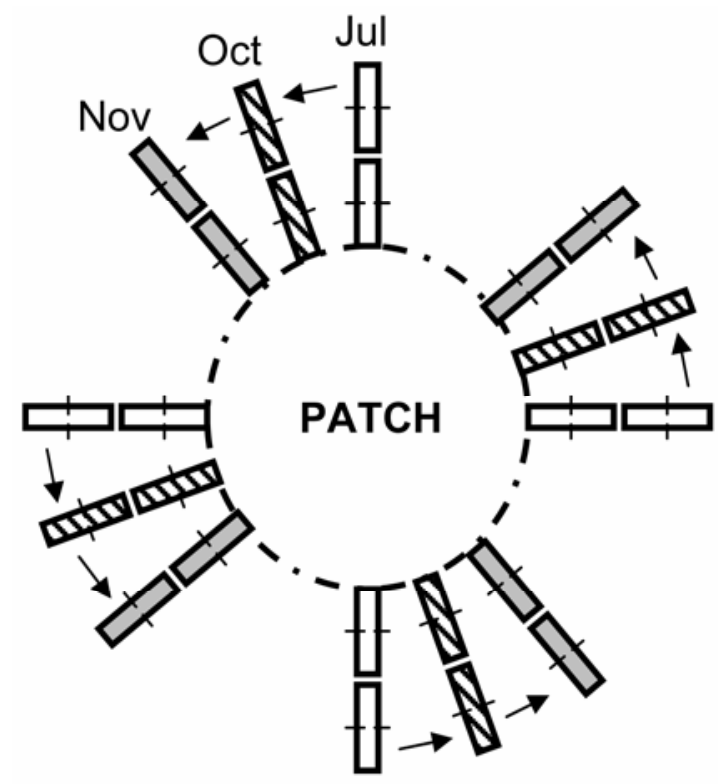

Fig. 1. Graphical representation of sampling scheme used for seasonal field studies (not to scale). Radiating outward from the circular patch, rectangular samples were taken at $90^{\circ}$ angles and each sample subdivided once. Successive seasonal samples were taken counterclockwise from the previous sample locations (arrows). Samples were taken in July (Jul, white), October (Oct, hatched), and November (Nov, gray). A slight modification was made for October and November 2004 (see text).
[Moorehead \& Co. Inc., Rocklin, CA]) and amended with the following: rifampicin at $100 \mu \mathrm{l} /$ liter $(1 \mathrm{~g} / 10 \mathrm{ml}$ of dimethyl sulfoxide stock solution; Sigma-Aldrich), ampicillin at $250 \mathrm{mg} / \mathrm{liter}$ (Sigma-Aldrich), and fenpropathrin at $100 \mu \mathrm{l} /$ liter (acetone stock solution at $15.4 \mathrm{mg}$ a.i./ml; Danitol 2.4EC; Valent Agricultural Products, Walnut Creek, CA). After 4 to 5 days, isolates resembling $O$. herpotricha were transferred to petri dishes containing PDARAD. Periodically, the nuclear ribosomal DNA from arbitrarily selected isolates was amplified by polymerase chain reaction using primers that distinguish species of Ophiosphaerella $(14,20)$ to confirm the identity of the fungi tentatively identified as $O$. herpotricha.

To determine the increase in patch size from the previous year, the plastic tarp used in 2003 was placed over the three patches again in early spring 2004 using the steel plates for reference. For each patch sampled in 2003, the increase in size was determined by measuring from the spring 2004 patch. Two patches were measured from the 2003 edge in four directions and the one damaged by herbicide in three directions. The outlines of all inoculated patches in the study area also were recorded.

In the summer and autumn of 2004, the same sampling process was repeated on three different patches $(60$ to $70 \mathrm{~cm}$ in diameter) in the same stand of turfgrass. Three different patches were selected because the removal of plants, soil, and $O$. herpotricha from the patches used in 2003 may have affected future disease activity in these patches. Samples were collected on edge of the 2003 patch to the edge of the 
the same dates and each patch was sampled in four directions. None of the patches or areas sampled displayed disease symptoms and were covered completely by apparently healthy bermudagrass. One modification was made for samples collected in October and November due to frequent detection of $O$. herpotricha in the 10.8 - to $21.6-\mathrm{cm}$ section from July 2004. Three soil samples were collected in each of four directions for each plot using a different soil profile sample probe (rectangular; 8.25 by 2.5 by 6 to $8 \mathrm{~cm}$, length by width by depth). Each of the three samples was cut in half ( 4.12 by $2.5 \mathrm{~cm})$ and processed as described previously. Soil temperatures were determined as described previously.

On 13 April 2005, three samples per patch (rectangular; 10.8 by 2.5 by 6 to 8 $\mathrm{cm}$, length by width by depth) were collected at the edge of the same three spring dead spot patches, divided once, and processed as described previously. To determine the increase in patch size, the plastic tarp used previously was placed over the three patches in spring 2005. For each patch sampled in 2004, the increase in size was determined by measuring from the spring 2004 patch edge in four directions to the 2005 edge. Data were analyzed using SAS (version 9.1; SAS Institute).

\section{RESULTS}

Growth chamber temperature studies. Bermudagrass growth varied between temperatures. Plant growth was greatest at 25 and $30^{\circ} \mathrm{C}$ and nearly nonexistent at $12^{\circ} \mathrm{C}$. Root colonization by $O$. herpotricha resulted in dark discoloration of roots, and colonization length varied by temperature (Table 1). After 8 days, colonization ranged from 6.5 to $12.0 \mathrm{~mm}$ for temperatures at or below $21^{\circ} \mathrm{C}$. Two days later, colonization generally was larger, ranging from 8.6 to $13.1 \mathrm{~mm}$ for temperatures at or below $21^{\circ} \mathrm{C}$. For both evaluations, lesion length was significantly greater at $17^{\circ} \mathrm{C}$ and much less for warmer temperatures.

Table 1. Influence of temperature (Temp) on the colonization of bermudagrass roots by Ophiosphaerella herpotricha under growth-chamber conditions

\begin{tabular}{lcc}
\hline & \multicolumn{2}{c}{ Lesion length $(\mathbf{m m})^{\mathbf{a}}$} \\
\cline { 2 - 3 } Temp $\left({ }^{\mathbf{}} \mathbf{C}\right)$ & $\mathbf{8 ~ d a y s}$ & $\mathbf{1 0}$ days \\
\hline 12 & 9.1 & 10.0 \\
16 & 7.8 & 9.8 \\
17 & 12.0 & 13.1 \\
19 & 6.5 & 8.6 \\
21 & 9.6 & 11.1 \\
25 & 2.9 & 2.6 \\
30 & 2.7 & 3.0 \\
Contrast & & \\
12 vs. 16 & $\mathrm{NS}$ & $\mathrm{NS}$ \\
17 vs. 21 & 0.015 & 0.04 \\
21 vs. 25 & 0.0001 & 0.0001 \\
25 vs. 30 & $\mathrm{NS}$ & $\mathrm{NS}$ \\
\hline
\end{tabular}

a Length determined 8 and 10 days after inoculation; NS = not significant.
After 8 days at 25 or $30^{\circ} \mathrm{C}$, colonization was less than $2.9 \mathrm{~mm}$ in length and remained small $(<3.0 \mathrm{~mm})$ when evaluated 2 days later.

Seasonal field studies. Fungal colonization of bermudagrass roots collected in July, October, and November 2003 were similar (Table 2). Recovery was greatest for samples collected closest to the edge of the spring patch for both July and October and declined as the distance increased away from the edge of the spring margin. In November, fungal colonization was greatest at 5.4 to $10.8 \mathrm{~cm}$ and declined with distance from the spring patch edge. In spring 2004, patch expansion increased an average of $9.9 \mathrm{~cm}$ from the 2003 patch edge.

In July 2004, samples collected out to $16.2 \mathrm{~cm}$ from the spring patches contained a similar percentage of roots colonized by $O$. herpotricha (Table 2). Samples collected more distal, at 16.2 to $21.6 \mathrm{~cm}$, had fewer colonized roots. A trend similar to that in 2003 was observed for samples collected in October and November 2004, with the frequency of colonized roots greatest near the patch edge and decreasing with distance away from the patch edge. However, the percentage of roots colonized in November was greater than in October, with greatest increase occurring from 4.12 to $12.4 \mathrm{~cm}$ (Table 3). In spring 2005, these patches increased an average of $21.4 \mathrm{~cm}$ from the 2004 patch edge.
Bermudagrass roots collected at the edge of the patches in spring 2005 contained 12.1 and $2.7 \%$ colonized roots for 0 to 5.4 and 5.4 to $10.8 \mathrm{~cm}$, respectively $(n=103)$.

\section{DISCUSSION}

It is well established that cool soil temperatures favor the development of bermudagrass spring dead spot $(4,12,15)$. Bermudagrass seedlings grown in growth chambers were colonized by $O$. herpotricha over a wide temperature range below $21^{\circ} \mathrm{C}$ that occasionally resulted in plant death (data not shown). Lesion length was dramatically smaller above $21^{\circ} \mathrm{C}$ and occurred only locally at the point of inoculation for 25 and $30^{\circ} \mathrm{C}$. This may have been a result of the mechanical disturbance caused by inoculation, given that the region remained similar between the two evaluation times. The temperatures conducive for disease shown in this study are consistent with those suggested by Smith (11) and Crahay et al. (2) for O. narmari and $O$. korrae, respectively. However, these results are not consistent with those of Tisserat et al. (15), who found similar root discoloration for the main effect for all treatments evaluated at both 15 and $25^{\circ} \mathrm{C}$. In our study, root growth and root system size at $25^{\circ} \mathrm{C}$ for inoculated and noninoculated plants were similar (data not shown), suggesting that the pathogen was not capable of affecting root growth at this temperature. Our data, as well as those

Table 2. Seasonal colonization of bermudagrass roots by Ophiosphaerella herpotricha in field plots in $2003^{\mathrm{a}}$

\begin{tabular}{lrrcccc}
\hline & \multicolumn{7}{c}{ Roots colonized (\%) } \\
\cline { 2 - 7 } Distance (cm) & July & SE & October & SE & November & SE \\
\hline $0-5.4$ & 22.7 & 8.3 & 19.4 & 5.3 & 15.3 & 4.0 \\
$5.4-10.8$ & 21.0 & 7.7 & 12.7 & 5.0 & 21.0 & 7.8 \\
$10.8-16.2$ & 3.2 & 2.3 & 3.1 & 2.1 & 5.5 & 2.8 \\
$16.2-21.6$ & 4.6 & 4.6 & 5.9 & 4.0 & 1.0 & 1.0 \\
\hline
\end{tabular}

a Number of roots placed on amended potato dextrose agar: $n=634,1,020$, and 927 for July, October, and November, respectively.

${ }^{b}$ Mean percent roots colonized from the edges of three spring dead spot patches sampled 11 times for each distance. $\mathrm{SE}=$ standard error of mean.

Table 3. Seasonal colonization of bermudagrass roots by Ophiosphaerella herpotricha in field plots in $2004^{\mathrm{a}}$

\begin{tabular}{lcccccc}
\hline & \multicolumn{7}{c}{ Roots colonized $(\boldsymbol{\%})^{\mathbf{b}}$} \\
\cline { 2 - 7 } Distance (cm) & July & SE & October & SE & November & SE \\
\hline $0-5.4$ & 26.7 & 7.8 & $\ldots$ & $\ldots$ & $\ldots$ & $\ldots$ \\
$5.4-10.8$ & 27.5 & 8.2 & $\ldots$ & $\ldots$ & $\ldots$ & $\ldots$ \\
$10.8-16.2$ & 31.0 & 9.1 & $\ldots$ & $\ldots$ & $\ldots$ & $\ldots$ \\
$16.2-21.6$ & 9.3 & 4.7 & $\ldots$ & $\ldots$ & $\ldots$ & $\ldots$ \\
$0-4.12^{\mathrm{c}}$ & $\ldots$ & $\ldots$ & 34.0 & 7.8 & 49.1 & 8.8 \\
$4.12-8.25$ & $\ldots$ & $\ldots$ & 31.0 & 7.2 & 50.4 & 8.8 \\
$8.25-12.4$ & $\ldots$ & $\ldots$ & 21.9 & 8.7 & 41.0 & 6.2 \\
$12.4-16.5$ & $\ldots$ & $\ldots$ & 14.6 & 6.2 & 20.4 & 4.7 \\
$16.5-20.6$ & $\ldots$ & $\ldots$ & 11.6 & 4.6 & 25.5 & 8.5 \\
$20.6-24.8$ & $\ldots$ & $\ldots$ & 9.7 & 4.4 & 12.0 & 5.1 \\
\hline
\end{tabular}

a Number of roots placed on amended potato dextrose agar: $n=370,603$, and 695 for July, October, and November, respectively.

${ }^{b}$ Mean percent roots colonized from the edges of three spring dead spot patches sampled 12 times for each distance. $\mathrm{SE}=$ standard error of mean.

${ }^{c}$ October and November sampling was performed with a different soil sampling probe. 
from previous studies $(2,11)$, suggest that the optimum temperature for disease caused by all species of Ophiosphaerella is similar and below 20 to $21^{\circ} \mathrm{C}$.

Based on soil temperature, a greater percentage of colonized roots was expected for both autumn sampling dates above that found in the July. This was not observed in 2003 , even though soil temperatures averaged 18.1 and $18.3^{\circ} \mathrm{C}$ at depths of 5 and $10 \mathrm{~cm}$, respectively, between October and November collection dates. In addition, a slight reduction in root colonization was observed in the autumn compared with July. In July and October 2004, the same trend was observed, with the percentage of roots colonized being similar for both dates. An increase in the percentage of roots colonized was observed for samples collected in November 2004. Soil temperatures for the period of time between sampling in October and November 2004 were nearly identical to 2003, with soil temperatures averaging 18.2 and $18.6^{\circ} \mathrm{C}$ at depths of 5 and $10 \mathrm{~cm}$, respectively. Also, the number of hours that soil temperatures were below $21^{\circ} \mathrm{C}$ at 5 and $10 \mathrm{~cm}$ between the October and November sampling dates was similar for both years and only differed by 6 and $15 \mathrm{~h}$ at 5 and $10 \mathrm{~cm}$, respectively, between the 2 years. The 30-year air temperature average for central Oklahoma during this period was $13.3^{\circ} \mathrm{C}$.

However, precipitation amount and frequency between autumn sampling dates was different between years and may explain, in part, the differences found in this study. The 30-year precipitation average for October and November in central Oklahoma is 8.8 and $6.6 \mathrm{~cm}$, respectively. In 2003, a total of $7.2 \mathrm{~cm}$ of precipitation accumulated in 4 events (precipitation within a calendar day) whereas, in 2004, $13.1 \mathrm{~cm}$ of precipitation accumulated in 14 events. The more frequent and greater amount of precipitation in 2004 may have created soil conditions more favorable for disease. Spring dead spot has been reported to be less severe in sandier soils (22) and there may be the possibility that factors that affect soil water, such as soil texture or rainfall, can influence $O$. herpotricha activity.

Although the stand was inoculated in all locations on the same date, rates of expansion differed for the two groups of patches selected for study in each year. The 200304 study patches were located at the edge of the bermudagrass planting and expanded more slowly $\left(0.13 \mathrm{~m}^{2}\right.$ per year $)$ than 2004-05 study patches $\left(0.23 \mathrm{~m}^{2}\right.$ per year), which were more central in the planting. Variability in root or stolon density across the planting was evident in the higher numbers of stolons and roots analyzed in 2003 than 2004 (Tables 2 and 3), and this may have contributed to the observed differences in disease patch sizes and rate of patch increase.
In both years, patch growth stayed within the distance of sampling. Plants closest to the spring patch edge generally had the highest percentage of roots colonized. In November 2004, eight soil samples collected from the inside of two patches had an average of $45 \%$ of the roots colonized (data not shown). This is similar to the frequency of colonized roots found in the 0- to $12.4-\mathrm{cm}$ sampling range. Samples collected at the outermost interval contained plants with the lowest percentage of infected roots. The root systems of plants in the same stand, which had never exhibited symptoms of spring dead spot, were not found to be colonized by $O$. herpotricha (data not shown). This study suggests that plants having a low level of colonization $(<10 \%)$ may survive. However, if the percentage of infected roots is greater than 10 to $15 \%$, then plants may not survive.

The presence of infected roots $20 \mathrm{~cm}$ away from the spring patch edge in July in both years suggests that extensive colonization and infection occurs in the spring. An increase in the percent infected roots in the expansion region was detected in autumn 2004; however, given the high level of infection in July, it is likely that these plants would not have survived even in the absence of fall activity. Spring fungicide applications have been reported to suppress disease severity the following year (K. Jackson, personal communication) and may have demonstrated the importance of spring disease activity when soil temperatures were cool. In addition, spring disease activity may explain the inconsistency in fall disease management efforts such as fungicide applications.

Bermudagrass regrowth into the spring dead spot patch often has been described as slow, with shallow and sparse rooting. These observations have led to speculation that a fungal toxin present in the soil inhibits plant growth $(5,17)$. An equally plausible explanation for slow plant growth is the concurrent infection and colonization of new roots by $O$. herpotricha combined with cool soil temperatures that are suboptimal for bermudagrass growth. Aggressive fertilization in the spring to maximize plant growth and fill-in of the patches while soil temperatures are still conducive for fungal infection may promote greater disease severity the following year. This effect has been recognized by some turfgrass managers who have attempted to minimize disease severity by withholding nitrogen fertilization until late spring, when soil temperatures are warmer.

It is feasible, based on soil temperatures, that spring dead spot has two primary periods of disease activity during a year in Oklahoma. As programs continue to evolve for the management of spring dead spot, it may be important to examine practices that can influence both spring and autumn disease activity. Plant cultural activities that occur during the summer that reduce the impact of fall or spring colonization or injury caused by $O$. herpotricha may be beneficial in reducing the affects of this disease the following year.

\section{ACKNOWLEDGMENTS}

Published with the approval of the Director, Oklahoma Agricultural Experiment Station, Stillwater. This project was supported in part the Oklahoma Agricultural Experiment Station project 2420. We thank K. J. Black for technical assistance with this study.

\section{LITERATURE CITED}

1. Baird, J. H., Martin, D. L., Taliaferro, C. M., Payton, M. E., and Tisserat, N. A. 1998. Bermudagrass resistance to spring dead spot caused by Ophiosphaerella herpotricha. Plant Dis. 82:771-774.

2. Crahay, J. N., Dernoeden, P. H., and O'Neill, N. R. 1988. Growth and pathogenicity of Lep tosphaeria korrae in bermudagrass. Plant Dis. 72:945-949.

3. Dernoeden, P. H., Crahay, J. N., and Davis, D. B. 1991. Spring dead spot and bermudagrass quality as influenced by nitrogen source and potassium. Crop Sci. 31:1674-1680.

4. Endo, R. M., Ohr, H. D., and Krausman, E. M. 1985. Leptosphaeria korrae, a cause of the spring dead spot disease of bermudagrass in California. Plant Dis. 69:235-237.

5. Fermanian, T. W. 1980. The isolation of a toxin from spring dead spot areas in bermudagrass (Cynodon L. C. Rich) turf. Ph.D. dissertation, Oklahoma State University, Stillwater.

6. Lucas, L. T. 1980. Spring dead spot of bermudagrass. Pages 183-187 in: Advances in Turfgrass Pathology. P. O. Larson and B. G. Joyner, eds. Harcourt Brace Jovanovich. Duluth, MN.

7. Martin, D. L., Bell, G. E., Baird, J. H., Taliaferro, C. M., Tisserat, N. A., Kuzmic, R. M. Dobson, D. D., and Anderson, J. A. 2001. Spring dead spot resistance and quality of seeded bermudagrasses under different mowing heights. Crop Sci. 41:451-456.

8. Pair, J. C., Crowe, F. J., and Willis, W. G. 1986. Transmission of spring dead spot disease of bermudagrass by turf soil cores. Plant Dis. 70:877-878.

9. Smiley, R. W., Dernoeden, P. H., and Clarke, B. C. 2005. Compendium of Turfgrass Disease, 3rd ed. American Phytopathological Society, St. Paul, MN.

10. Smith, A. M. 1965. Ophiobolus herpotrichus, A cause of spring dead spot in couch turf. Agric. Gaz. N. S. W. 76:753-758.

11. Smith, A. M. 1971. Control of spring deadspot of couch grass in New South Wales. J. Sports Turf Res. Inst. 47:60-65.

12. Smith, A. M. 1971. Spring dead spot of couch grass turf in New South Wales. J. Sports Turf Res. Inst 47:54-59.

13. Tisserat, N. A., and Fry, J. 1997. Cultural practices to reduce spring dead spot (Ophiosphaerella herpotricha) severity in Cynodon dactylon. Int. Turf. Res. J. 8:931-936.

14. Tisserat, N. A., Hubert, S, H., and Sauer, K. M. 1994. Selective amplification of rDNA internal transcribed spacer regions to detect Ophiosphaerella korrae and O. herpotricha. Phytopathology 84:478-482.

15. Tisserat, N. A., Pair, J. C. and Nus, A. 1989 Ophiosphaerella herpotricha, a cause of spring dead spot of bermudagrass in Kansas. Plant Dis. 73:933-937.

16. Unruh, J. B., Gaussoin, R. E., and Wiest, S. C., 1996. Basal growth temperatures and growth rate constants of warm-season turfgrass species. Crop Sci. 36:997-999.

17. Venkatasubbaiah, P., Tisserat, N. A., and Chilton, W. S. 1994. Metabolites of Ophiosphae- 
rella herpotricha, a cause of spring dead spot of bermudagrass. Mycopathologia 128:155159.

18. Wadsworth, D. F., and Young. H. C. 1960. Spring dead spot of bermudagrass. Plant Dis. 44:516-518.

19. Walker, J., and Smith, A. M. 1972. Leptosphaeria narmari and L. korrae sp. nov., two long-spored pathogens of grasses in Australia. Trans. Br. Mycol. Soc. 58:459-466.

20. Wetzell, H. C., III, Hubert, S. H., and Tisserat N. A. 1999. Molecular evidence for the presence of Ophiosphaerella narmari n. comb., a cause of spring dead spot of Bermuda grass in North America. Mycol. Res. 103:981-989.

21. Wetzell, H. C., III, Skinner, D. Z., and Tisserat
N. A. 1999. Geographic distribution and genetic diversity of three Ophiosphaerella species that cause spring dead spot of bermudagrass. Plant Dis. 83:1160-1166.

22. Young, H. C., Sturgeon, R. V., Jr., and Huffine, W. W. 1973. Soil type associated with spring dead spot of bermudagrass. (Abstr.) Phytopathology 63:450 